\title{
Cumulative cognitive impairment following recurrent severe hypoglycaemia in adult patients with insulin-treated diabetes mellitus
}

\author{
S.J.Langan ${ }^{1}$, I.J.Deary ${ }^{1}$, D. A. Hepburn ${ }^{2}$ and B.M. Frier ${ }^{2}$ \\ ${ }^{1}$ Department of Psychology, University of Edinburgh, Edinburgh and \\ ${ }^{2}$ Diabetic Department, Royal Infirmary, Edinburgh UK
}

\begin{abstract}
Summary. To examine the hypothesis that episodes of severe hypoglycaemia may cause cumulative cognitive impairment, 100 Type 1 (insulin-dependent) diabetic patients were examined. Their age range was 25-52 years, and the onset of diabetes had occurred after the age of 19 years. Patients with evidence of organic brain disease, including cerebrovascular disease, were excluded. A questionnaire was used to assess the number, frequency and severity of hypoglycaemic episodes experienced during treatment with insulin and the accuracy of this retrospective information was verified from general practice and hospital case-notes. A detailed neuropsychological assessment was undertaken, including tests of pre-morbid and present IQ (Wechsler-Revised), memory and information-processing speed. Significant correlations were observed between the frequency of severe hypoglycaemia and the magnitude of intellectual decline, Performance IQ, inspection time and reaction time (patients with
\end{abstract}

the more frequent hypoglycaemia had poorer performance). Two sub-groups of patients were identified on the basis of their experience of severe hypoglycaemia, and were balanced for pre-morbid IQ, age and duration of diabetes. One sub-group $(n=23)$ had never experienced severe hypoglycaemia (Group A), whilst the other sub-group $(n=24)$ had suffered at least five episodes of severe hypoglycaemia (Group B). Group B had greater intellectual impairment than Group A, and Group B also had a significantly slower mean reaction time and higher reaction time variance when compared with Group A. It is concluded that recurrent severe hypoglycaemia is associated with cumulative cognitive impairment in adult diabetic patients treated with insulin.

Key words: Hypoglycaemia, insulin, diabetes mellitus, cognitive function, intelligence, reaction time, inspection time.
The brain is vitally dependent on glucose for its normal function and is neither able to store this substrate in any quantity, nor can it synthesise glucose during acute deprivation. Depletion of the supply of glucose to the brain rapidly causes impaired neuronal function, manifested by acute neuroglycopenia, but it is not known whether this can cause any permanent or cumulative damage, resulting in a decline in intellectual capacity. Acute hypoglycaemia is a common side-effect of the treatment of diabetes with insulin, and the intensification of insulin regimens to achieve optimal glycaemic control has increased the risk of hypoglycaemia by 2-3 times [1]. Complete clinical recovery from acute hypoglycaemia is usually rapid and has encouraged the assumption that severe episodic hypoglycaemia does not cause permanent cerebral damage. However, neuropathology studies of diabetic patients with fatal hypoglycaemia have demonstrated widespread areas of damage within the brain $[2,3]$. In addition to the direct effect of low blood glucose on neuronal function, it has been suggested that severe hypoglycaemia may precipi- tate acute vascular events [4], and cerebral ischaemia and convulsions both occur during severe hypoglycaemia [5]. Prolonged severe hypoglycaemia in animals produces specific damage to the central nervous system, particularly when combined with hypoxia $[6,7]$.

It is possible that repeated exposure to acute hypoglycaemia may cause cumulative damage to the brain which is not clinically evident in the short-term. This may be analogous to the progressive deterioration in intellectual function which is demonstrable following chronic exposure to various other insults such as alcohol [8], hypoxia induced by sleep apnoea [9], exposure to high altitude [10], or trauma from recurrent head injury [11]. Occasionally diabetic patients in clinical practice describe a subjective diminution in intellectual abilities following isolated episodes of severe prolonged hypoglycaemia, but such individual instances are anecdotal and the degree of impairment has rarely been quantified. Most research on cognitive function during hypoglycaemia in humans has been confined to an examination of acute and relatively 
Table 1. The clinical characteristics of the whole sample of diabetic patients and of the patients in Group A (no hypoglycaemia) and Group B (at least five episodes of severe hypoglycaemia)

\begin{tabular}{|c|c|c|c|}
\hline & $\begin{array}{l}\text { Group A } \\
(n=24)\end{array}$ & $\begin{array}{l}\text { Group B } \\
(n=23)\end{array}$ & $\begin{array}{l}\text { Whole sample } \\
(n=100)\end{array}$ \\
\hline \multicolumn{4}{|l|}{ Demographics } \\
\hline $\begin{array}{l}\text { Age in years (mean, } S D) \\
\text { Sex ratio }(M: F)\end{array}$ & $\begin{array}{l}37.9(6.4) \\
14: 10\end{array}$ & $\begin{array}{l}38.5(5.3) \\
11: 12\end{array}$ & $\begin{array}{l}40.2(6.4) \\
57: 43\end{array}$ \\
\hline \multicolumn{4}{|c|}{ Type 1 diabetes characteristics (mean, SD) } \\
\hline $\begin{array}{l}\text { Duration (years) } \\
\text { Blood glucose } \\
\mathrm{HbA}_{1}(\%) \\
\text { Daily insulin dose (units) } \\
\text { Insulin index }{ }^{\mathrm{a}}(\mathrm{U} / \mathrm{kg})\end{array}$ & $\begin{array}{l}10.7(4.0) \\
11.8(5.2) \\
10.0(2.3) \\
52.3(23.9) \\
0.7(0.2)\end{array}$ & $\begin{array}{l}13.0(4.0) \\
11.6(5.7) \\
10.2(1.8) \\
55.7(26.7) \\
0.8(0.2)\end{array}$ & $\begin{array}{l}13.4(6.2) \\
11.5(5.1) \\
10.2(1.9) \\
55.2(21.4) \\
0.8(0.2)\end{array}$ \\
\hline \multicolumn{4}{|l|}{ Physical characteristics (mean, SD) } \\
\hline $\begin{array}{l}\text { Weight }(\mathrm{kg}) \\
\text { Height }(\mathrm{m}) \\
\text { Body mass index }{ }^{b}\left(\mathrm{~kg} / \mathrm{m}^{2}\right) \\
\text { Systolic BP (seated) }\left(\mathrm{mm} \mathrm{Hg}^{2}\right) \\
\text { Diastolic BP (seated) }(\mathrm{mm} \mathrm{Hg})\end{array}$ & $\begin{aligned} 75.1 & (14.6) \\
1.71 & (0.09) \\
25.7 & (4.1) \\
131.4 & (19.7) \\
81.4 & (12.9)\end{aligned}$ & $\begin{aligned} 71.2 & (14.0) \\
1.68 & (0.11) \\
25.2 & (3.4) \\
123.1 & (10.5) \\
80.0 & (8.6)\end{aligned}$ & $\begin{array}{r}73.5(13.1) \\
1.69(0.09) \\
25.7(3.6) \\
128.8(15.2) \\
81.9(10.7)\end{array}$ \\
\hline \multicolumn{4}{|c|}{ Diabetic complications (number of cases) } \\
\hline $\begin{array}{l}\text { Retinopathy } \\
\text { Peripheral neuropathy } \\
\text { Autonomic neuropathy } \\
\text { Nephropathy } \\
\text { Hypoglycaemic unawareness }\end{array}$ & $\begin{array}{l}2 \\
1 \\
1 \\
2 \\
1\end{array}$ & $\begin{array}{l}7 \\
0 \\
1 \\
0 \\
2\end{array}$ & $\begin{array}{r}22 \\
4 \\
5 \\
2 \\
4\end{array}$ \\
\hline
\end{tabular}

modest decrements in blood glucose [12-16]. These studies have confirmed the short-lived effects of neuroglycopenia on cognitive function but provide no evidence for the potentially adverse effects of recurrent hypoglycaemic insults to the brain. However, a small number of studies [17-20] has attempted to ascertain whether hypoglycaemia leaves permanent intellectual impairment.

Although these studies have some limitations they suggest that insulin-treated diabetic patients do suffer mild cognitive damage, the cause of which might be related to severe hypoglycaemia. One method of assessing cognitive impairment is to estimate IQ decrement. The present study was undertaken to examine whether repeated exposure to severe hypoglycaemia had affected cognitive functioning in diabetic patients treated with insulin. Patients with childhood onset of diabetes were excluded from the study. A group of adult insulin-treated diabetic patients underwent assessment of cognitive function, using a series of standard psychometric and computerised tests. These patients were carefully screened to exclude factors other than hypoglycaemia which might have affected cognitive function, and evidence of intellectual impairment was examined with respect to the estimated frequency and severity of their previous exposure to severe hypoglycaemia.

\section{Subjects and methods}

One hundred insulin-treated diabetic patients $(57 \mathrm{M}, 43 \mathrm{~F})$ were recruited at the Diabetic Department of the Royal Infirmary of Edinburgh. The age range of the patients was 25 to 52 years (mean 40 , SD 6.4). All the patients had Type 1 (insulin-dependent) diabetes mellitus, the onset of which had occurred after 19 years of age, with a duration of at least 5 years (mean 13, SD 6.2). This age range ensured that all patients had achieved cognitive maturity before developing diabetes but had not developed significant age-related in- tellectual decline. The minimum duration of diabetes ensured that all patients had been exposed to the risk of insulin-induced hypoglycaemia for at least 5 years, before assessment.

All patients who met the strict exclusion criteria were selected. Patients were excluded from the study if they had a history of cerebrovascular disease or previous head injury, serious systemic disease, major psychiatric illness, or if they were taking medications which might alter cognitive function, such as psychotropic drugs, beta-adrenergic blockers or steroids. A history of epilepsy or chronic excessive drinking of alcohol were also exclusion factors, as was a visual acuity poorer than $6 / 9$ (which would have interfered with the ability to perform some of the tests of cognitive function). Current alcohol consumption was documented by the use of a structured questionnaire which estimated the number of units of alcohol which patients drank per week. Excessive drinking was defined using the standard guidelines of the Royal College of Psychiatrists (UK).

All patients were examined to identify the presence of diabetic complications and the co-existence of other medical problems such as hypertension and macrovascular disease. Physical examination was performed by an experienced diabetologist, and included direct ophthalmoscopy, biochemical screening and measurement of urinary albumin excretion rates on timed overnight urine collections. Clinical characteristics of the patients are shown in Table 1. None of the patients had clinical evidence of macrovascular disease, although some had microangiopathy. No distinction was made between background and (treated) proliferative retinopathy.

Written informed consent and Ethical Committee approval was obtained prior to the study being carried out.

Table 2. The frequency of severe hypoglycaemia within the group of 100 Type 1 (insulin-dependent) diabetic patients (shown as percentages)

\begin{tabular}{lr}
\hline More than one episode per week & 0 \\
More than one episode per month & 1 \\
4 to 12 episodes per year & 5 \\
1 to 3 episodes per year & 23 \\
Less than one episode per year & 45 \\
Never experienced severe hypoglycaemia & 26 \\
\hline
\end{tabular}


Table 3. Pearson (and partial) correlations between IQ test results and indices of hypoglycaemia (decimal points omitted). For sub. test correlations WAIS-R raw scores were used

\begin{tabular}{lccc}
\hline & $\begin{array}{l}\text { Frequency of } \\
\text { severe hypo- } \\
\text { glycaemia }\end{array}$ & $\begin{array}{l}\text { Number of severe } \\
\text { hypoglycaemic } \\
\text { episodes in life }\end{array}$ & $\begin{array}{l}\text { Number of mild } \\
\text { hypoglycaemic } \\
\text { episodes in } 8 \text { weeks }\end{array}$ \\
\hline NART (estimated) IQ & $14(09)$ & $-13(04)$ & $-06(04)$ \\
WAIS-R Performance IQ & $26^{\mathrm{c}}(32)^{\mathrm{d}}$ & $-12(-07)$ & $-05(07)$ \\
WAIS-R Verbal IQ & $03(06)$ & $-04(05)$ & $-08(-06)$ \\
IQ 'impairment' & $-24^{\mathrm{b}}(-33)^{\mathrm{d}}$ & $07(10)$ & $-10(-06)$ \\
WAIS-R performance sub-tests & & & \\
Picture completion & $23^{\mathrm{b}}(21)^{\mathrm{a}}$ & $-13(-08)$ & $-05(-03)$ \\
Block design & $27^{\mathrm{c}}(30)^{\mathrm{c}}$ & $-14(-10)$ & $-04(-05)$ \\
Object assembly & $21^{\mathrm{a}}(24)^{\mathrm{b}}$ & $-05(-02)$ & $01(-01)$ \\
Digit symbol & $28^{\mathrm{c}}(23)^{\mathrm{b}}$ & $-27^{\mathrm{c}}(-08)$ & $05(17)$ \\
WAIS-R verbal sub-tests & & $-05(10)$ & $-12(-06)$ \\
Information & $04(00)$ & $-11(-01)$ & $-06(-01)$ \\
Vocabulary & $10(09)$ & $-05(06)$ & $01(06)$ \\
Arithmetic & $03(04)$ & $-06(00)$ & $-07(-07)$ \\
Comprehension & $02(06)$ & $-14(02)$ & $02(08)$ \\
Similarities & $14(09)$ &
\end{tabular}

\section{Estimates of hypoglycaemia}

Patients were interviewed using a questionnaire to assess the number, frequency and severity of hypoglycaemic episodes during treatment with insulin. A 'mild' episode of hypoglycaemia was defined as one which was self-treated, during which there had been no alteration in conscious level, while a 'severe' episode required external assistance for recovery, whether or not loss of consciousness had occurred. Three variables were obtained from the questionnaire: lifetime frequency of severe hypoglycaemic episodes; lifetime total number of severe episodes; and the number of mild and severe episodes in the preceding 8 weeks.

Two sub-groups of patients were identified who either had experienced no previous episodes of severe hypoglycaemia $(n=24$, Group A), or who had a history of several previous episodes (five or more) of severe hypoglycaemia ( $n=23$, Group B). The groups were balanced for pre-morbid IQ, age, duration of diabetes and social class. To attempt verification of the information obtained by the questionnaire on hypoglycaemia, the general-practice records and hospital out-patient and in-patient case-notes of these patients were scrutinized for documentary evidence of previous episodes of severe hypoglycaemia. In addition, relatives were questioned about the incidence and severity of nocturnal hypoglycaemia. We were able to confirm that the diabetic patients who reported having experienced multiple episodes of severe hypoglycaemia had required treatment on several occasions, although the exact number of episodes experienced in a lifetime could not be ascertained with accuracy because of incomplete documentation or treatment in other centres. Some general practitioners confided that they did not always enter a written record in the patient's file of emergency treatment of acute hypoglycaemia. Of the 24 diabetic patients who claimed never to have experienced severe hypoglycaemia, evidence to the contrary was obtained for only one patient. This individual was recorded to have experienced three hypoglycaemic episodes of moderate severity, associated with alcohol consumption, and had on one occasion taken an intentional overdose of insulin. Each of these episodes had been treated with oral carbohydrate.

\section{Assessment of cognitive ability}

The Wechsler Adult Intelligence Scale-Revised (WAIS-R; [21]) was used to assess current intellectual level. Verbal, Performance and Full scale IQs were obtained. Performance sub-tests used were: Picture Completion, Block Design, Object Assembly and Digit Symbol.
The following Verbal sub-tests were used: Information, Vocabulary, Arithmetic Comprehension and Similarities.

The National Adult Reading Test (NART; [22]) was used to assess pre-morbid IQ, i.e. the peak cognitive level attained by the patient prior to any cognitive deterioration. This estimate of IQ is resistant to organic brain damage and correlates highly with WAIS-R IQ in healthy adults [23].

The Rey Auditory Verbal Learning Test (AVLT; [24]) was used to assess both short- and long-term memory. Patients were given five trials to learn a list of 15 words which they were asked to recall (a) immediately, (b) after interference, and (c) after a 30 minute delay.

The Borkowski Verbal Fluency Test (controlled association) [25] is thought to assess frontal lobe function. Patients were given $60 \mathrm{~s}$ to state as many words as possible, beginning with letters specified by the tester.

Inspection Time (IT; [26]) was used to assess perceptual speed. Patients were asked to discriminate the spatial position (left or right) of the longer of two briefly-presented vertical lines of markedly different lengths. The stimuli were backward-masked, the presentation duration was varied, and the amount of time needed to make a reliable discrimination $(85 \%$ correct) is termed the patient's 'inspection time'.

Reaction Time (RT). A delay in reaction time is a common characteristic of brain damage. A four-Choice reaction time test was used, and separate decision and movement times were obtained. Decision times and their standard deviations tend to be related to higher cognitive functions [27].

The Paced Auditory Serial Addition Task (PASAT; [28]) was used to assess concentration and attention. This has proved to be sensitive in detecting the mild cognitive deficits associated with closed head injury. Patients listened to a list of numbers which were then added together according to a given rule. After practice, two trials of $61 \mathrm{di}-$ gits were performed with 4 and 2 seconds between successive digits, respectively.

Cognitive impairment: In the past IQ decrement scores were calculated by subtracting the scores of those WAIS subtests which deteriorated with ageing from those which did not [29]. This method was largely replaced by the use of demographic indices to estimate premorbid IQ, from which current IQ scores might be subtracted to give a decrement score $[23,29]$. More recently, the NART has been shown to be a more accurate estimate of pre-morbid IQ than demo- 
Table 4. Pearson (and partial) correlations between measures of information processing and indices of hypoglycaemia (decimal points omitted)

Table 5. Pearson (and partial) correlations between memory, verbal fluency and hypoglycaemia indices (decimal points omitted)

\begin{tabular}{|c|c|c|c|}
\hline & $\begin{array}{l}\text { Frequency of } \\
\text { severe hypo- } \\
\text { glycaemia }\end{array}$ & $\begin{array}{l}\text { Number of severe } \\
\text { hypoglycaemic } \\
\text { episodes in life }\end{array}$ & $\begin{array}{l}\text { Number of mild } \\
\text { hypoglycaemic epi- } \\
\text { sodes in } 8 \text { weeks }\end{array}$ \\
\hline Inspection time & $-11(-20)^{a}$ & $08(11)$ & $-01(-07)$ \\
\hline RT-median decision time & $-34^{\mathrm{d}}(-26)^{\mathrm{c}}$ & $15(10)$ & $03(07)$ \\
\hline $\begin{array}{l}\text { RT-decision time standard } \\
\text { deviation }\end{array}$ & $-28^{c}(-23)^{a}$ & $29^{\mathrm{c}}(40)^{\mathrm{d}}$ & $07(15)$ \\
\hline RT-median movement time & $-20^{\mathrm{a}}(-30)^{\mathrm{c}}$ & $-01(07)$ & $10(21)^{\mathrm{a}}$ \\
\hline PASAT (4 seconds) & $02(-01)$ & $-09(-05)$ & $10(05)$ \\
\hline PASAT ( 2 seconds) & $17(18)$ & $-21^{a}(-20)^{a}$ & $05(-03)$ \\
\hline
\end{tabular}

${ }^{\mathrm{a}} p<0.05,{ }^{\mathrm{b}} p<0.02,{ }^{\mathrm{c}} p<0.01,{ }^{\mathrm{d}} p<0.001$, two-tailed.

RT - Reaction Time

PASAT - The Paced Auditory Serial Addition Task

\begin{tabular}{llll}
\hline & $\begin{array}{l}\text { Frequency of } \\
\text { severe hypo- } \\
\text { glycaemia }\end{array}$ & $\begin{array}{l}\text { Number of severe } \\
\text { hypoglycaemic } \\
\text { episodes in life }\end{array}$ & $\begin{array}{l}\text { Number of mild } \\
\text { hypoglycaemic epi- } \\
\text { sodes in 8 weeks }\end{array}$ \\
\hline Memory & $04(-02)$ & $-12(-04)$ & $08(11)$ \\
Rey AVLT, Trial 1 & $18(08)$ & $-21^{\mathrm{a}}(-05)$ & $04(13)$ \\
Rey ALVT, Trial 5 & $03(09)$ & $-08(13)$ & $04(11)$ \\
Rey AVLT, Trial B & $10(03)$ & $-13(01)$ & $07(13)$ \\
Rey AVLT, Trial 6 & $10(11)$ & $-08(-04)$ & $06(05)$ \\
Rey AVLT, Trial 7 & & & \\
Verbal fluency & $03(00)$ & $07(11)$ & $02(01)$ \\
Letter 'J' & $07(08)$ & $-02(03)$ & $09(13)$ \\
Letter 'S' & $02(-03)$ & $01(15)$ & $09(17)$ \\
Letter 'U' & $07(11)$ & $09(08)$ & $14(15)$ \\
Letter 'M' & & &
\end{tabular}

${ }^{a} p<0.05$, two-tailed.

AVLT = Auditory Verbal Learning Test graphic variables, at least in the UK population [30]. Therefore, in the present study, an IQ decrement index was obtained for individual patients by subtracting current Performance IQ (WAIS-R) from the NART estimated (pre-morbid) Performance IQ. The estimate of pre-morbid IQ (the NART) was originally standardised on the WAIS prior to revision. The WAIS and the NART IQ measures over-estimate the WAIS-R IQ by seven points [21]. Therefore, the NART IQ estimates were adjusted by seven points for all subjects in the present study.

Glycaemic control: Blood glucose was measured at the time of psychological testing to ensure that no patient had biochemical hypoglycaemia, and total glycated haemoglobin $\left(\mathrm{HbA}_{1}\right)$ was also estimated by electroendosmosis using commercially available agar plates (normal range 5-8\%). Mean values are shown in Table 1 . The $\mathrm{HbA}_{1}$ results over the preceding year were also reviewed to assess preceding glycaemic control.

\section{Statistical analysis}

A correlational design was used. Pearson correlations were computed to establish whether a relationship existed between the psychological variables and the hypoglycaemic indices for the full sample of 100 patients. The potentially confounding effects of age, duration of diabetes or prevailing blood glucose (at the time of cognitive assessment), were excluded from correlations between intellectual performance and the indices of hypoglycaemia by the use of partial correlation.

In order to demonstrate the extent of any cognitive impairment demonstrated by correlation, a second type of analysis was undertaken. As described above, between-group analyses (using independent $t$-tests) were carried out on the sub-groups of diabetic patients at the high and low extremes for exposure to severe hypoglycaemia. The study population was divided approximately into quartiles, representing increasing experience of severe hypoglycaemia. The upper and lower quartiles represented those subjects who had experienced five or more severe hypoglycaemic episodes in their lifetime, and those who had never experienced a severe hypoglycaemic episode, respectively. The fact that five episodes was chosen was arbitrary, and served only to produce two balanced, equal-sized groups with different experiences of hypoglycaemia. Two-tailed tests of significance were used thoughout.

\section{Results}

The incidence of severe hypoglycaemia in the group of 100 diabetic patients is shown in Table 2 .

\section{Intellectual functioning}

The Pearson and partial correlations between intellectual functions and the frequency of severe hypoglycaemia are shown in Table 3. The other indices of hypoglycaemia did not correlate significantly with the psychological variables, but the results of statistical analyses employing these indices are shown in all Tables. A significant correlation was obtained between the frequency of severe hypoglycaemia and the degree of intellectual impairment $(r=-0.24, p<0.02)$, and with Performance IQ $(r=0.26$, $p<0.01$ ), but not with Verbal IQ. Therefore, patients with more frequent severe hypoglycaemia had a greater degree of intellectual impairment. This impairment consisted of a reduction in Performance IQ, with preservation of Verbal 


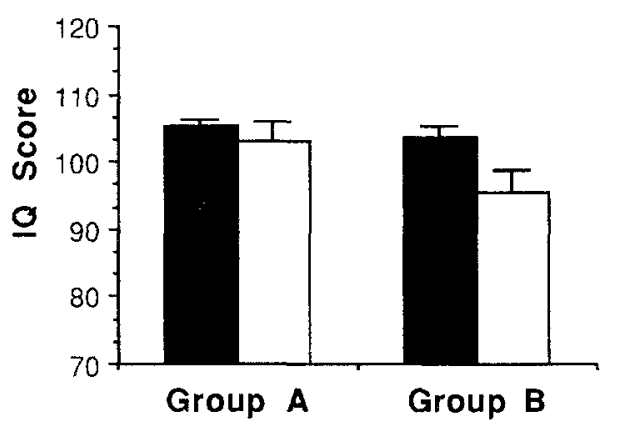

Fig. 1. Pre-morbid (black bars) and present IQ levels (white bars) for Group A (patients with no history of severe hypoglycaemia) and Group B (patients with at least five episodes of severe hypoglycaemia). Pre-morbid vs present IQ comparison for Group $A$ is nonsignificant, comparison for Group B is significant at $p<0.01$
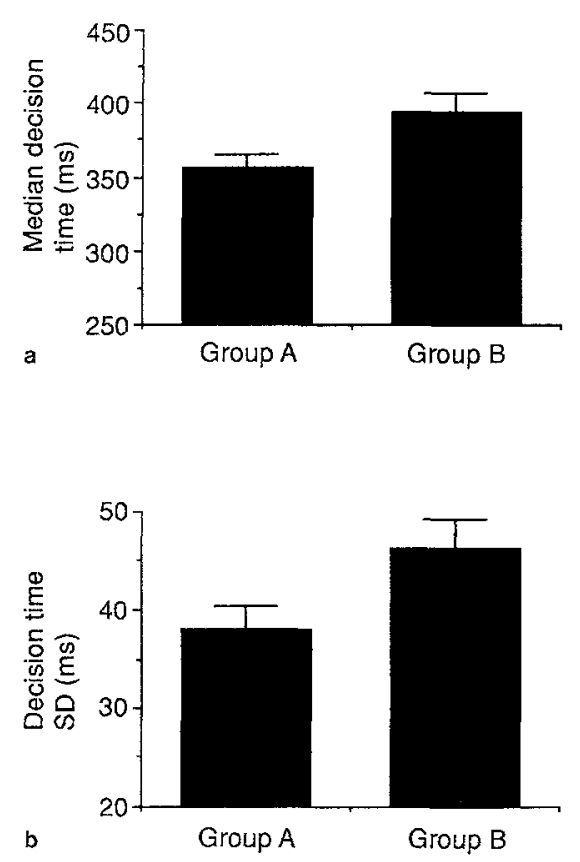

Fig. 2 a, b. Group A (no hypogiycaemia) and Group B (five or more episodes of severe hypoglycaemia) compared on (a) decision time $(p<0.02)$ and $(\mathbf{b})$ decision time standard deviation $(p<0.03)$ on the four-choice reaction time test

IQ. All correlations between frequency of severe hypoglycaemia and WAIS-R Performance subtest raw scores are significant, while all of the Verbal subtests show nearto-zero correlations. These correlations were maintained when partial correlations were performed, suggesting that the relationship between the frequency of severe hypoglycaemia and intellectual function is not attributable to any of the confounding effects of age, duration of diabetes or the blood glucose concentration at the time of testing.

\section{Information processing}

The Pearson and partial correlations between information processing measures and hypoglycaemia indices are shown in Table 4 . In the choice reaction time test significant correlations were observed between the frequency of severe hypoglycaemia and both the median decision time $(r=-0.34, p<0.001)$ and the movement time $(r=$ $-0.20, p<0.05)$. Decision time standard deviation correlated significantly with both frequency $(r=-0.28$, $p<0.01)$ and number $(r=0.29, p<0.01)$ of severe hypoglycaemia episodes. A significant correlation was observed between inspection time and frequency of severe hypoglycaemia $(r=-0.20, p<0.05)$ only after the effects of age, duration of diabetes and blood glucose were partialled out. Therefore, the diabetic patients who had a history of frequent severe hypoglycaemia had a slower mean speed of, and greater variance in, information processing.

The PASAT test scores correlated significantly with the estimated total number of hypoglycaemic episodes in a lifetime $(r=-0.21, p<0.05)$, and tended to do so with the frequency of severe hypoglycaemia $(r=-0.17$, $p<0.1$ ).

\section{Memory and verbal fluency}

The Pearson and partial correlations between estimates of memory and verbal fluency and the frequency of severe hypoglycaemia are shown in Table 5. No more significant correlations than would be expected due to chance were observed between these variables, suggesting that memory and verbal fluency had not been impaired by exposure to recurrent severe hypoglycaemia.

\section{Between-group analyses}

To demonstrate the extent of the intellectual impairment established by correlational analysis, the two sub-groups of patients (Groups A and B) were examined. Patients with a history of five or more severe hypoglycaemic episodes had an IQ decrement of 7.9 points (over half a standard deviation, $p<0.01$, Fig. 1), whereas those with no episodes of severe hypoglycaemia fell from pre-morbid IQ levels by a mean of only 2.1 points (NS). Therefore, patients exposed to multiple episodes of severe hypoglycaemia lost 5.8 IQ points more than those with no history of severe hypoglycaemia, and this difference tended toward significance (Fig. $1 ; t=1.71, p<0.1$ ). The two subgroups tended to differ in Performance IQ $(t=1.80$, $p<0.1$ ). Furthermore, the group with previous severe hypoglycaemia exhibited significantly slower decision times $(t=2.44, p<0.02$, Fig. 2 a) and greater decision time standard deviations $(t=2.19, p<0.03$, Fig. $2 b)$, and tended to have slower movement times $(t=1.78, p<0.08)$ in the choice reaction time test. No other between group comparisons were significant.

\section{Discussion}

The potentially cumulative deleterious effect of repeated episodes of severe hypoglycaemia on cognitive function has been examined previously in diabetic patients. Bale, using a word learning test, reported that 17 of a group of 100 adult diabetic patients scored within the "brain-dam- 
aged" range [17]. Their impaired performance appeared to be associated with an increased number and severity of episodes of preceding hypoglycaemia, but other conditions such as co-existing cerebrovascular disease were not excluded. Bale estimated the IQ decrement of 15 of the 17 'damaged' diabetic patients by subtracting their Wechsler Adult Intelligence Scale (WAIS) Performance IQ from their WAIS Verbal IQ. He found only one patient who had a "significant" IQ loss of 28 points. A decrement of this magnitude is very large and would not be expected following a moderate number of episodes of severe hypoglycaemia. We have re-analysed Bale's published data and found that the mean IQ decrement in the 15 diabetic patients tested on the WAIS was 5 IQ points, which would be significant if it could be replicated in a larger group. A study by Franceschi et al. [18] suggested that some factor associated with diabetes results in poorer cognitive performance, but it failed to exclude causes other than hypoglycaemia.

Contrary to Bale [17], Lawson et al. [19] concluded that cognitive deficit was not a cardinal feature of a diabetic clinic population. However, an IQ decrement is usually recorded when a subject suffers organic brain damage after having attained full cognitive development. This may have been precluded in some of Lawson's diabetic subjects because patients with an onset of diabetes as early as 6 years of age were included. Wredling et al. [20] reported that insulin-dependent diabetic patients with recurrent and severe hypoglycaemia scored lower on tests of motor ability, memory and general problem solving than a matched group with no severe hypoglycaemia. This is a potentially important result because there appear to be few confounding variables in the study and the cognitive deficit appears to be attributable to the preceding hypoglycaemia. They concluded that the cognitive differences of the two groups were not related to pre-morbid intellectual status which was not estimated using a direct test, but was inferred from level of education.

The results of the present study suggest that the frequency of severe hypoglycaemia is significantly related to the observed degree of intellectual impairment, and to measurements of Performance IQ, inspection time and reaction time. By partialling out potentially confounding variables from the correlations, and by adhering to rigorous exclusion criteria to avoid the possible effects of other organic cerebral disease, it appeared that the relationship between the frequency of severe hypoglycaemia and cognitive function could not be attributed to age, duration of diabetes or transient derangement of blood glucose control. The correlations between the psychological variables and the indices of hypoglycaemia are not high, partly as a result of the limited reliability of the assessment of the frequency of hypoglycaemia and possibly because hypoglycaemia may not be the only cause of intellectual deficit. However, the magnitude of the correlations is less important than the potential replicability of these relationships which often achieved high levels of significance. Because large numbers of patients were involved in the significant correlations, the $95 \%$ confidence intervals are very small, and do not include zero, suggesting that these results will be replicable. The measure of cognitive decline employed in this study is an improvement upon previous measures of IQ decrement, and relies upon the observation that the NART gives an accurate estimate of pre-morbid IQ after an individual has undergone cognitive decline. Without this measure of cognitive decline the question of whether low IQ led to more episodes of severe hypoglycaemia rather than the converse would have remained open and unanswered.

Correlational analysis, involving a large number of patients, was used to establish the relationship between hypoglycaemia and a reduction in cognitive function. Furthermore, by comparing patients who had never experienced severe hypoglycaemia with patients who had experienced five or more episodes of severe hypoglycaemia the extent of this impairment was demonstrated. The two groups were balanced for potentially confounding variables. This approach demonstrated that those diabetic patients who had experienced multiple severe episodes tended to have a significant reduction in intellectual capacity (over half a standard deviation on the IQ scale), and had declined by 5.8 IQ points more than the group with no severe hypoglycaemia. The group exposed to severe hypoglycaemia also tended to exhibit reductions in Performance IQ and reaction time. This study has demonstrated a cumulative deficit attributable to multiple severe hypoglycaemic insults, but does not indicate the possible degree of intellectual impairment which may occur in individual diabetic patients following an isolated hypoglycaemic coma.

One major difficulty of any retrospective study of this nature is the problem of accurate recall by the patients of the number of severe episodes of hypoglycaemia which may have occurred over several years. After reviewing the three estimates obtained from our hypoglycaemia questionnaire, with respect to their accuracy of recall and their relevance to organic brain damage, it was concluded that 'frequency of severe hypoglycaemia' offered the best combination of reliability and validity, and that this explains why it was the measure which most often correlated significantly with cognitive test scores. Patients found that it was relatively easy to recall their approximate frequency of severe hypoglycaemia, but a retrospective determination of the total number of severe episodes over several years of treatment was very difficult. The number of episodes of hypoglycaemia in the preceding 8 weeks was easy to recall and was probably very accurate, but the episodes were so few in number that this measure was not considered to be relevant to an assessment of the role of hypoglycaemia in causing progressive and cumulative organic brain damage over several years. In an attempt to validate our estimates of hypoglycaemia, the clinical records of those 47 patients who were included in the group analyses were examined in detail. Some general practitioners admitted that a written record of emergency treatments in the community was not always made in the patient's case records, which thereby diminished the number of recorded events. Despite these difficulties with incomplete documentation, we were able to verify that the two groups who reported either never having experienced severe hypoglycaemia or having been exposed to multiple episodes, had provided highly accurate information, 
which was consistent with their allocation to each group on historical grounds. In all but one case the data obtained from the medical records was in perfect agreement with the information provided by the patients.

The findings of the present study are congruent with the studies of diabetic adults by Bale [17] and Wredling et al. [20], and support observations in diabetic children, which indicate that a relationship exists between a history of recurrent severe hypoglycaemia and intellectual status [31-33]. The present study suggests intellectual deficits induced by hypoglycaemia may occur in adults who develop diabetes after cerebral maturity has occurred. This progressive reduction in IQ related to hypoglycaemia has implications for individuals in occupations which depend heavily on intellectual function and which require the application of reasoning and judgement to novel material. Patients who are performing at the limits of their intellectual capacity might decline below a threshold of competence as a result of hypoglycaemia-induced cognitive impairment. This would reduce their efficiency and could jeopardize their employment. IQ may be compromised further in diabetic patients by the supervening effects of age and the development of premature cerebrovascular disease.

While this study does not provide incontrovertible proof that recurrent hypoglycaemia directly damages cerebral function, the results do suggest an association between frequency and severity of neuroglycopenia and a decline in cognitive function. Diabetic patients on intensified insulin regimens experience more severe hypoglycaemia than on conventional therapy, and this problem may be compounded by the development of counterregulatory hormonal deficiencies and hypoglycaemia unawareness [34]. Many patients are at risk of experiencing prolonged and severe hypoglycaemic coma, with the potential result of inducing permanent and cumulative intellectual deficit. Although this conclusion was supported by Wredling et al. they were unable to exclude conclusively the possibility that those subjects with more severe hypoglycaemia have lower pre-morbid levels of ability [20]. Prospective diabetic management with insulin should therefore take into account the possible long-term consequences of severe and frequent hypoglycaemia, which should be avoided at all costs.

The design of this study overcomes some of the deficiencies of previous studies: confounding effects were eliminated, modern IQ decrement estimates were used, a large number of subjects was studied, an attempt was made to quantify each subject's experience of hypoglycaemia, and a time-consuming, rigorous check was made on the validity of the retrospective reports of hypoglycaemia in approximately half of the subjects. It will take a prolonged prospective study, which will estimate the number and intensity of hypoglycaemic episodes in patients over several years [1], to provide definitive evidence, but the significance levels of our findings indicate that there is sufficient validity in detailed retrospective reports to conduct useful research in this area.

Acknowledgements. This research was supported by the Scottish Hospital Endowments Research Trust (SHERT Grant 949). We thank Dr. R. Prescott for statistical advice during the design and analysis stages of the study, and Drs. O. Boland and I. Scougal for assistance with medical examinations.

\section{References}

1. The DCCT Research Group (1987) The Diabetes Control and Complications Trial (DCCT): Results of feasibility study. Diabetes Care 10:1-19

2. Lawrence RD, Meyer A, Nevin S (1942) The pathological changes in the brain in fatal hypoglycaemia. Q J Med 35 (NS 11): 181-201

3. Patrick AW, Campbell IW (1990) Fatal hypoglycaemia in insulintreated diabetes mellitus - clinical features and neuropathological changes. Diabetic Med 7: 349-354

4. Frier BM, Hilsted J (1985) Does hypoglycaemia aggravate the complications of diabetes? Lancet II: $1175-1177$

5. Hepburn DA, Steel JM, Frier BM (1989) Hypoglycemic convulsions cause serious musculoskeletal injuries in patients with IDDM. Diabetes Care 12: 32-34

6. Brierly JB (1981) Brain damage due to hypoglycaemia. In: Marks V, Rose FC (eds) Hypoglycaemia, 2nd edn. Blackwell, Oxford, pp 488-494

7. Auer RN, Olsson Y, Siesjo BK (1984) Hypoglycaemic brain injury in the rat. Correlation of density of brain damage with the EEG isoelectric time: a quantitative study. Diabetes 33: 10901098

8. Ryan C, Butters N (1984) Alcohol consumption and premature ageing: a critical review. Recent Dev Alcohol 2: 223--250

9. Greenberg GD, Watson RK, Deptula D (1987) Neuropsychological dysfunction in sleep apnea. Sleep 10:254-262

10. Nelson M (1982) Psychological testing at high altitudes. Aviat Space Environ Med 53: 122-126

11. Gronwall D, Wrightson P (1981) Memory and information processing capacity after closed head injury. J Neurol Neurosurg Psychiatry 44: 889-895

12. Pramming $S$, Thorsteinson $B$, Theilgaard A, Pinner EM, Binder C (1985) Cognitive function during hypoglycaemia in Type 1 diabetes mellitus. Br Med J 291:376-379

13. Holmes CS, Hayford JT, Gonzalez JL, Weydert JA (1983) A survey of cognitive functioning at different glucose levels in diabetic persons. Diabetes Care 6: 180-185

14. Herold KC, Polonsky KS, Cohen RM, Levy J, Douglas F (1985) Variable deterioration in cortical function during insulin-induced hypoglycaemia. Diabetes 34:677-685

15. Holmes CS, Koepke HM, Thompson RG, Gyres PW, Weydert JA (1984) Verbal fluency and naming performance in Type 1 diabetes at different blood glucose concentrations. Diabetes Care 7: 454-459

16. Hoffman RG, Speelman DJ, Hinnen DA, Conley KL, Guthrie RA, Knapp RK (1989) Changes in cortical functioning with acute hypoglycaemia and hyperglycaemia in Type 1 diabetes. Diabetes Care 12: 193-197

17. Bale RN (1973) Brain damage in diabetes mellitus. Br J Psychiatry 122: $337-341$

18. Franceschi M, Cecchetto R, Minicucci F, Smizne S, Baio G, Canal $N$ (1984) Cognitive processes in insulin-dependent diabetes. Diabetes Care 7: 228-231

19. Lawson JS, Williams Erdahl DL, Monga TN, Bird CE, Donald MW, Surridge DHC, Letemendia FJJ (1984) Neuropsychological function in diabetic patients with neuropathy. Br J Psychiatry $145 ; 263-268$

20. Wredling R, Levander S, Adamson U, Lins PE (1990) Permanent neuropsychological impairment after recurrent episodes of severe hypoglycaemia in man. Diabetologia 33:152-157

21. Wechsler D (1981) Manual for the Wechsler adult intelligence scale-revised. Psychological Corporation, New York

22. Nelson HE (1982) National Adult Reading Test (NART): test manual. NFER-Nelson, Windsor 
23. Crawford JR (1989) Estimation of premorbid IQ: a review of recent developments. In: Crawford JR, Parker DM (eds) Developments in clinical and experimental neuropsychology. Plenum, New York, pp 55-74

24. Lezack MD (1983) Neuropsychological assessment, 2nd edn. Oxford University Press, Oxford, pp 422-429

25. Borkowski JD, Benton AL, Spreen O (1967) Word fluency and brain damage. Neuropsychologia 5: 135-140

26. Brand CR, Deary IJ (1982) Intelligence and inspection time. In: Eysenck HJ (ed) A model for intelligence. Springer, Berlin Heidelberg New York, pp 133-148

27. Jensen AR (1982) Reaction time and psychometric g. In: Eysenck HJ (ed) A model for intelligence. Springer, Berlin Heidelberg New York, pp 93-132

28. Gronwall D (1977) Paced auditory serial addition test: a measure of recovery from concussion. Percept Mot Skills 44: 367-373

29. Chelune GJ, Ferguson W, Moehle K (1986) The role of standard cognitive and personality tests in neuropsychological assessment. In: Incagnoli T, Goldstein G, Golden CJ (eds) Clinical application of neuropsychological test batteries. Plenum, New York, pp 75-120

30. Crawford JR, Stewart LE, Parker DM, Besson JAO, Cochrane RHB (1989) Estimation of premorbid intelligence: combining psychometric and demographic approaches improves predictive accuracy. Personal Individ Diff 10: 793-796

31. Ryan C, Vega A, Drash A (1985) Cognitive deficits in adolescents who developed diabetes early in life. Pediatrics 75:921-927

32. Ryan CM (1988) Neurobehavioural complications in Type 1 diabetes: examination of possible risk factors. Diabetes Care 11: 86-93

33. Rovet JF, Ehrlich RM, Hoppe M (1987) Intellectual deficits associated with early onset of insulin-dependent diabetes mellitus in children. Diabetes Care 10: 510-515

34. Frier BM (1986) Hypoglycaemia and diabetes. Diabetic Med 3: $513-525$

Received: 10 September 1990

and in revised form: 14 December 1990

Dr. I.J. Deary

Department of Psychology

University of Edinburgh

7 George Square

Edinburgh EH8 9JZ

Scotland

UK 